\title{
PENGEMBANGAN PERANGKAT PEMBELAJARAN WATER FLOW CONTROL DALAM MATA KULIAH SISTEM KONTROL PROSES DI JURUSAN TEKNIK ELEKTRO UNESA
}

\author{
Yulia Fransisca, Rifqi Firmansyah \\ Jurusan Teknik Elektro Universitas Negeri Surabaya \\ yuliafransisca@unesa.ac.id , \\ rifqifirmansyah@unesa.ac.id
}

\begin{abstract}
Abstrak - Penelitian ini bertujuan membuat perangkat pembelajaran dan jobsheet pada mata kuliah sistem kontrol proses. Selain untuk membuat perangkat juga untuk menguji kelayakan dan respon mahasiswa terhadap hasil penelitian. Penelitian ini menggunakan metode R\&D (research and development) terdiri dari sepuluh langkah-langkah, akan tetapi kami hanya melakukan hingga tujuh tahapan saja berikut: 1) analisis potensi dan masalah, 2) perencnaan, 3) pengembangan produk awal, 4) validai produk awal, 5) revisi produk awal, 6) uji coba produk, dan 7) analisis dan pelaporan. Variable yang digunakan dalam yaitu laju aliran air. Untuk menguji tingkat kelayakan perangkat pembelajaran dan jobsheet, di dapatkan dari penilaian dosen yaitu tiga dosen FT UNESA sepuluh mahasiswa sistem kontrol dan instrumentasi angkatan 2016. Berdasarkan hasil penelitian diperoleh kesimpulan, penilaian terhadap perangkat untuk keseluruhan sangat baik dengan penilaian $88,33 \%$ dan penilaian jobsheet untuk sangat baik dengan penilaian $89,33 \%$. Respon mahasiswa dinyatakan baik dengan penilaian 83,66\%. Dengan hasil tersebut dapat disimpulkan bahwasannya perangkat dan jobsheet cocok diaplikasikan sebagai media ajar pada mata kuliah sistem kontrol proses.
\end{abstract}

Kata Kunci: sistem, proses, laju aliran, $R \& D$, perangkat.

\begin{abstract}
This research aims to make learning device and job sheet on course system of process control. In addition to making the device also to examine the feasibility and the response of the students against the results of the research. This research uses the method $R \& D$ (research and development) consists of ten steps, but we only do up to seven stages the following course: 1) the analysis of the potential and the problems of design, 2), 3) initial product development, 4) validate the initial product, 5) revision of the initial product, 6) product trials, and 7) analysis and reporting. Variable used in IE the rate of water flow. To test the feasibility of device-level learning and job sheet, at the got from three assessment lecturer FT UNESA ten students of control systems and Instrumentation 2016 host. Based on the research results obtained in conclusion, the assessment of the overall device for very well with $\mathbf{8 8 . 3 3 \%}$ assessment and assessment job sheet for good by scoring $89.33 \%$. Student response expressed both with $83.66 \%$ assessment. With these results it can be concluded that the device and the fit was applied as job sheet media teaching on the course system of process control.
\end{abstract}

Keywords: System, process, flow rate, $R \& D$, device

\section{PENDAHULUAN}

Pendidikan sering dikenal dengan dua proses yang pertama adalah proses belajar dan yang kedua adalah proses mengajar (Sadirman, 2007:1). Belajar adalah sebuah proses mencari motivasi pengetahuan, tingkah laku dan kebiasaan (R.Gagne, 2002:22). Media pembelajaran adalah Alat, metode, dan teknik yang digunakan dalam rangka lebih mengefektifkan komunikasi dan interaksi antara guru dan siswa dalam proses pendidikan dan pengajaran di sekolah (Oemar Hamalik, )
.Adapun manfaat media pembelajaran yaitu: (1). Untuk menumbuhkan minat belajar pembelajaran harus dibuat lebih menarik. (2). Agar mudah dipahami bahan pembelajaran harus memeiliki makna yang jelas. (3). Metode ajar yang memiliki variasi, sehingga siswa tidak bosan dan pengajar tidak membutuhkan banyak energi. (4). Siswa dapat melaksanakan berbagai metode pembelajaran. (Azhar, 2009:4).

Menurut hasil pengamatan di Jurusan Teknik Elektro Unesa, metode pengajaran konvensional masih dilaksanakan dalam mata kuliah Sistem Kontrol Proses yakni metode ceramah 
namun kini mahasiswa dituntut menguasai metode dan juga dapat mengaplikasikan metode, sehingga diharapkan dapat menjadi penunjang yang baik untuk kebutuhan pembelajaran mahasiswa yang dapat dioperasikan sehingga mahasiswa dapat mudah memahami proses pemasangan hingga operasi dan output yang dapat diamati.

Pada penelitian ini, akan dirancang sebuah perangkat pembelajaran mata kuliah sistem Kontrol Proses. Sistem yang dirancang adalah miniatur dari perangkat asli, menggunakan metode Research and Development yang di dalamnya terdapat sepuluh tahapan, untuk penelitian ini hanya tujuh tahapan yang dilaksanakan, berikut: 1) potensi dan masalah 2) perencanaan 3) pengembangan produk awal 4) validasi produk awal 5) revisi produk awal 6) uji coba produk 7) analisis dan pelaporan hasil.

\section{Sensor Water Flow}

Water Flow sensor adalah sensor digital yang dapat mengukur debit air. Memiliki tingkat stabilitas yang baik serta mudah digunakan bersama dengan arduino. (Kumar, 2017).

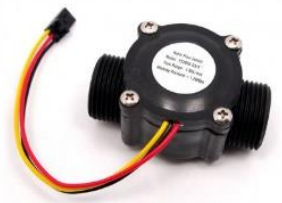

Gambar 1 Sensor Water Flow

Sensor Water Flow termasuk sensor yang menghasilkan data berupa pulsa bersamaan dengan derasnya aliran air yang mengalir maka pulsa akan semakin lebar.

Tabel 1 Spesifikasi Sensor Water Flow

\begin{tabular}{cc}
\hline Tipe & YSF-S201 $1 / 2$ “" \\
\hline Tegangan Kerja & $5-24 \mathrm{~V}$ \\
\hline Arus Maksimum & $15 \mathrm{~mA}$ \\
\hline Berat & $43 \mathrm{gr}$ \\
\hline Range debit aliran & $1-30 \mathrm{~L} / \mathrm{min}$ \\
\hline Temperatur kerja & $0-80^{0} \mathrm{C}$ \\
\hline Maksimum tekanan kerja & $1.2 \mathrm{Mpa}$ \\
\hline
\end{tabular}

\section{Arduino Uno R3}

Unit mikrokontroller menggunakan arduino uno r3. Arduino difungsikan untuk membaca data keluaran dari water flow sensor kemudian mengolahnya agar bisa disesuaikan dengan motor servo dan ditampilkan pada LCD.

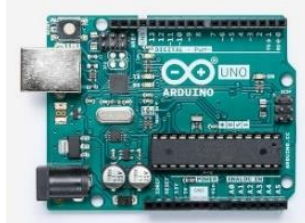

Gambar 2 Arduino Uno R3
Arduino Uno R3 memiliki 14 pin I/O. Arduino uno mempunyai semua kebutuhan yang dibutuhkan untuk mendukung mikrokontroller, termasuk koneksi dengan komputer melalui komunikasi serial .

Tabel 2 Spesifikasi Arduino UNO R3

\begin{tabular}{cc}
\hline Mikrokontroller & Atmega328P \\
\hline Tegangan Input & $5 \mathrm{~V}$ \\
\hline Range Tegangan Input & $6-20 \mathrm{~V}$ \\
\hline Pin Input/Output & $14 \mathrm{pin}$ \\
\hline Pin Input/Output (arus) & $20 \mathrm{~mA}$ \\
\hline Pin 3.3 V (arus) & $50 \mathrm{~mA}$ \\
\hline Memory Flash & $32 \mathrm{~KB}$ \\
\hline Clock Speed & $16 \mathrm{MHz}$ \\
\hline
\end{tabular}

\section{LCD 16x2}

Liquid Crystal Display (LCD) yaitu komponen elektronik sebagai penampil data. LCD dikembangkan dengan teknologi yang bekerja memantulkan cahaya yang berada di sekeliling perangkat, di dalam modul terdapat mikrkontroller untuk pengendali tampilan karakter, dilengkapi dengan memori dan register, sehingga pengguna dapat langsung menggunakannya.

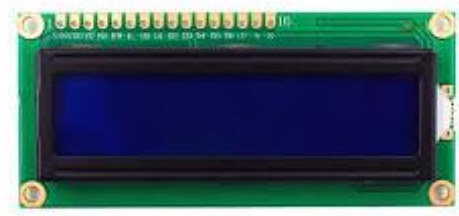

Gambar 3 LCD 16x2

Pin jalur input LCD diantaranya adalah: Pin data utuk data karakter yang akan ditampilkan dengan data 8 bit. Pin Read/Write sebagai instruksi, perintah low ditulis data, sedangkan perintah high untuk membaca data. Pin E (Enable) digunakan untuk memegang data baik masuk atau keluar. Pin RS sebagai indikator atau penentu jenis data yang masuk, logika low untuk perintah dan logika high untuk data masuk. Pin VLCD untuk mengatur brightness lcd, sedangkan tegangan masukan LCD sebesar 5 Volt.

\section{Motor Servo}

Ialah alat elektronik terdiri dari motor DC, gear, rangkaian dan variable resistor, dengan sistem feedback control, sehingga dapat diatur untuk menentukan dan mengetahui posisi sudut dari poros motor. 


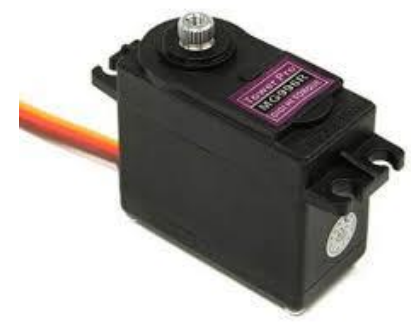

Gambar 4 Motor Servo

Dalam penelitian ini kami menggunakan motor servo sebagai penggerak valve atau kran air guna menyesuaikan aliran air yang keluar sehingga pengaturan aliran air dapat disesuaikan dari hasil pembacaan sensor sebelumnya dan proses buka tutup valve di sesuaikan oleh motor servo.

Tabel 4 Spesifikasi Motor Servo

\begin{tabular}{cc}
\hline Motor Servo & MG996R \\
\hline Modulasi & Digital \\
\hline Torsi & $9,4-11 \mathrm{~kg}-\mathrm{cm}$ \\
\hline Speed & $0,15-0,19 \mathrm{sec} / 60^{0}$ \\
\hline Dimensi & $40,7 \times 19,7 \times 42,9$ \\
\hline Pulsa & $1 \mathrm{~ms}$ \\
\hline Tipe Konektor & JR \\
\hline Tipe Gear & Metal
\end{tabular}

\section{Metode R\&D}

Untuk menghasilkan dan menguji keefektifan produk tertentu metode penelitian dan pengembangan ialah metode yang terbaik [3], diawali dengan kata research yang memiliki fungsi untuk mendapatkan informasi tentang kebutuhan atau dalam penelitian ini disebut analisis mengenai media pembelajaran pada mata kuliah tertentu. Sedangkan kata development dilakukan untuk menghasilkan suatu produk dari hasil research yang sebelumnya, dengan kata lain sangat saling membutuhkan.

Terdapat 10 tahapan penelitian dan pengembangan [5],yaitu: (1) Research and information collecting-Includes review of literature, classroom observation and preparation of report of state of the art. (2) Planning-Includes defining skills, stating objectives determining course sequence and small scale feasibility testing. (3) Develop preliminary form of productIncludes preparation of instructional materials, handbooks and evaluation devices. (4) Preliminary field testing-Conducted in form 1 to 3 schools, using 6 to 12 subjects. Interview, observational and questionnaire data collected and analyzed. (5) Main product revision-Revision of product as suggested by the preliminary field-test result. (6) Main field testingConducted 5 to 15 school with 30 to 100 subjects. Quantitative data on subjects precourse and postcourse performance are compared with control group data, when appropriate. (7) Operational product revisionrevision of product as suggested by main field-test results (8) Operational field
testingConducted in 10 to 30 schools involving 40 to 200 subjects. Interview, observational and questionnaire data collected and analyzed. (9) Final product revision-Revision of product as suggested by operational field-test result. (10) Dissemination and implementationReport on product at professional meeting and journals. Work with publisher who assumes commercial distribution. Monitor distribution to provide quality control.

\section{METODE}

Penelitian pengembangan merupakan jenis penelitian yang digunakan dalam penelitian ini dengan mengadopsi metode Borg and Gall. Dengan membuat media belajar sistem kontrol proses, sebagai media pembelajaran yang merupakan miniatur seperti yang ada di industri.

Tahapan pengembangan dan penelitian terbagi menjadi dua, tahap pertama difokuskan pada desain dan pengujian. Tahap kedua analisa terhadap kesesuaian ketika diaplikasikam dalam media pembelajaran.

\section{Subjek Penelitian}

Mahasiswa dengan bidang konsentrasi sistem kontrol dan instrumentasi angkatan 2016 menjadi subjek pada penelitian ini.

\section{Waktu Penelitian}

Peneliti melakukan penelitian dimuali pada bulan Maret hingga Oktober 2018 yang masuk dalam tahun ajaran 2017/2018

\section{Tempat Penelitian}

Peneliti melakukan penelitian di ruangan A8.03.15 FT UNESA

\section{Rancangan Penelitian}

Penggunaan metode R\&D adalah metode yang digunakan dalam penelitian ini dengan langkah-langkah seperti pada gambar 5

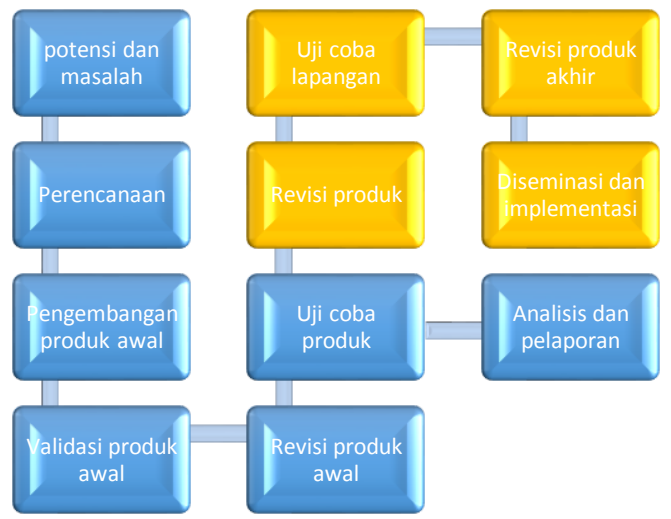

Gambar 5 Tahap penelitian R\&D 
Penelitian ini menggunakan tujuh tahap pada metode $R \& D$ yaitu: potensi dan masalah, perencanaan, pengembangan produk, validasi awal produk, revisi awal produk, uji coba produk. Sementara untuk 4 tahap yang tidak digunakan diganti dengan tahap analisis dan pelaporan karena hasil dari penelitian atau perangkat digunakan untuk media pembelajaran, tidak dilakukan produksi untuk kalangan masyarakat.

\section{HASIL DAN PEMBAHASAN}

Dosen elektro UNESA menjadi validator penelitian ini yang dimana berjumlah 3 dosen. Adapun keterangan validator, sebagai berikut;

Tabel 5 Nama-nama validator trainer dan jobsheet

\begin{tabular}{lll}
\hline No. & Nama Validator & Keterangan \\
\hline 1 & $\begin{array}{l}\text { Rifqi Firmansyah, S.T., } \\
\text { M.T. }\end{array}$ & Dosen Pengaturan \\
\hline 2 & $\begin{array}{l}\text { Farid Baskoro, S.T., } \\
\text { M.T. }\end{array}$ & Dosen Telematika \\
\hline 3 & $\begin{array}{l}\text { Arif Widodo, S.T., } \\
\text { M.Sc. }\end{array}$ & Dosen Elektronika \\
\hline
\end{tabular}

Dari keseluruhan menghasilkan nilai dan dikonversi dengan rating, selanjutnya hasil rating tersebut akan dikategorikan dengan skala likert.

\section{Validasi Perangkat}

Aspek penilaian validator dengan perangkat yaitu: kesesuaian perangkat dengan kurikulum mata kuliah, desain dan kualitas perangkat serta kesesuaian perangkat dengan jobsheet. Untuk hasil penilaian validasi perangkat ditunjukkan pada Gambar 6.

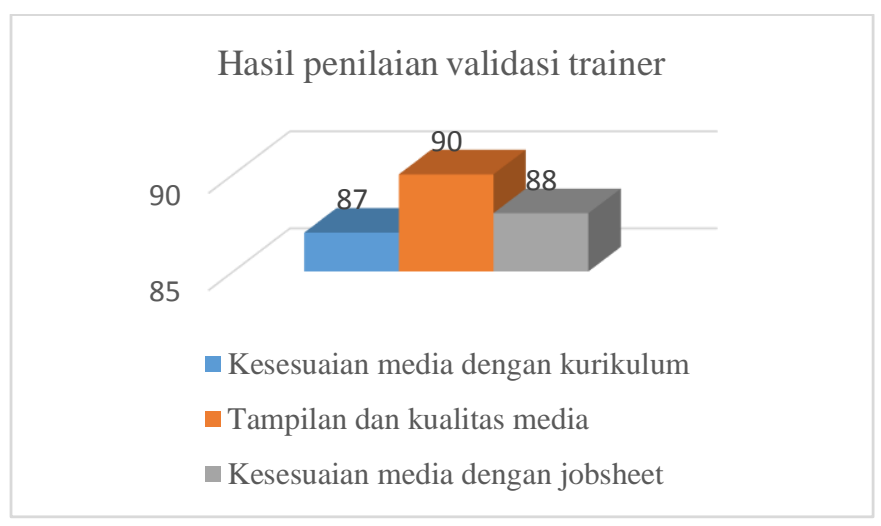

Gambar 6 hasil validasi perangkat

Dari penilaian validasi terhadap perangkat yaitu, kesesuaian perangkat dengan kurikulum sebesar $87 \%$, desain dan kwalitas perangkat sebesar $90 \%$, dan kesesuaian antara perangkat dan jobsheet sebesar $88 \%$. rata-rata penilaian keseluruhan perangkat adalah,

$$
\frac{\text { Shasil rating penilaian }}{\text { jumlah aspek penilaian }}=\frac{97 \%+90 \%+88 \%}{3}=88.33 \%
$$

Diperoleh hasil penilaian validasi perangkat sebesar 88,3\%. Disesuaikan dengan skala likert perangkat dapat dikategorikan dengan nilai kategori sangat baik, yang artinya perangkat dapat digunakan sebagai media ajar pada mata kuliah sistem kontrol proses.

\section{Validasi Jobsheet}

Aspek penilaian validator dengan jobsheet yaitu: Sesuaikah dengan kurikulum, desain dan Tingkat kesulitan untuk difahami. Untuk mendapatkan penilaian valid terdapat beberapa kriteria penilaian. Berikut hasil penilaian validasi jobsheet ditunjukkan pada Gambar 7

\section{Hasil penilaian validasi jobsheet}

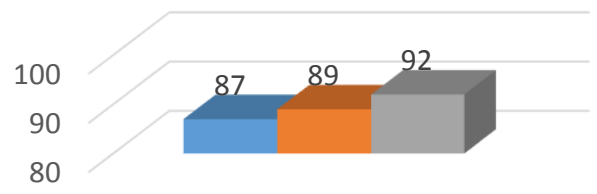

- Kesesuaian jobsheet dengan kurikulum

- Tampilan jobsheet

Kemudahan dalam pemahaman

Gambar 7 hasil validasi jobsheet

Gambar 7 merupakan hasil validasi terhadap jobsheet yaitu, kesesuaian dengan kurikulum sebesar $87 \%$, desain 89 $\%$, dan Tingkat tidak sulit untuk difahami sebesar $92 \%$. Kemudian dapat di rata-rata dari hasil penilaian adalah.

$$
\frac{\text { Shasil } \text { rating penilaian }}{\text { jumlah aspek penilaian }}=\frac{87 \%+89 \%+92 \%}{3}=89,33 \%
$$

Hasil keseluruhan penilaian validasi jobsheet sebesar $89,33 \%$, oleh karena itu jobsheet dapat dikategorikan pada penilaian kategori sangat baikdengan itu jobsheet dapat atau dapat digunakan sebagai jobsheet pada mata kuliah sistem kontrol proses.

\section{Hasil Respon Mahasiswa}

Hasil respon mahasiswa terhadap perangkat dan jobsheet, menggunakan lembar penilaian respon mahasiswa, instrumen penilaian lembar penilaian respon untuk perangkat dan jobsheet diisi oleh 10 mahasisawa sistem kontrol dan instrumentasi FT UNESA yang telah dilaksanakan beberapa pengujian perangkat dan jobsheet. Kemudian penilaian respon mahasiswa dapat dilihat pada Gambar 8 


\section{Hasil respon mahasiswa}

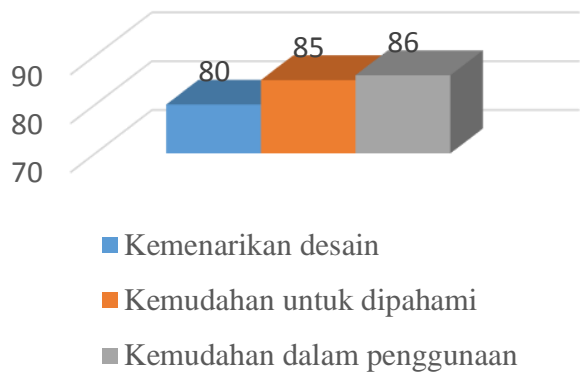

Gambar 8 hasil respon mahasiswa

Gambar 8 merupakan hasil respon mahasiswa terhadap perangkat dan jobsheet dengan rincian aspek yang dinilai yaitu, Kemenarikan desain perangkat memperoleh rating sebesar $80 \%$, Kemudah untuk dipahami rating sebesar $85 \%$, Kemudahan dalam penggunaan rating sebesar $86 \%$

Berdasarkan aspek penilaian respon mahasiswa, diperoleh hasil keseluruhan respon mahasiswa $83,66 \%$. Sehingga dapat dikategorikan nilai baik (skala likert).

\section{PENUTUP}

\section{Kesimpulan}

Dari hasil penelitian membuahkan perangkat ajar dan jobsheet sistem kontrol proses. Indikator dari penelitian adalah perangkat dan jobsheet sistem kontrol proses, penilaian perangkat, penilaian jobsheet dan penilaian mahasiswa

Dari hasil penelitian perangkat dikategorikan baik serta dapat digunakan, dengan nilai $88,33 \%$ untuk perangkat dan $89,33 \%$ untuk jobsheet. Penilaian medapat respon yang baik dari mahasiswa dengan hasil 83,66\% sesuai dengan kategori baik.

\section{Saran}

Berdasarkan dari beberapa langkah yang telah dilaksanakan, maka dapat disimpulkan sebagai berikut.: Penelitian ini hanya menguji perangkat dan jobsheet, kemudian belum diketahui efek dari penggunaan perangkat dan jobsheet terhadap individu mahasiswa. Perangkat dan jobsheet dapat dikembangkan lagi dengan menambah cabang dari aliran dan jumlah sensor yang digunakan.

\section{DAFTAR PUSTAKA}

[1] Sadiman, Arief, Media pendidikan (Pengertian, Pengembangan dan Pemanfaatannya). Indonesia, 2007

[2] Djamrah, Saiful Bahri, Psikologi Belajar. Jakarta, Indonesia, 2002.

[3] Sugiono, Media Penelitian Pendidikan Pendekatan Kuantitatif, Kualitatif, dan R\&D. Bandung, Indonesia 2009.

[4] Arsyad, Ashar, Media Pembelajaran. Pekan Baru, Indonesia 2010.

[5] Borg.W.R dan Gall, M.D. Educational Research An Introduction. New York, USA 1983

[6] Manjit Kaur,Ria Sood, Design and Development of Automatic Water Flow, Journal of IJCSEA, vol.3, No.3, 2013
[7] Pengju Zhang, Real time dc servo motor positin control by PID controller using Labview. International Conference on Inteligent Human -Machine System, 2009

[8] Kuganesan Kumar, Moamin A. Mahmoud. Monitoring and Controlling Tap Water Flow at Homes Using Android Mobile Application. American Journal of Software Engineering and Applications. Vol. 6, No. 6, 2017, pp. 128-136. doi: 10.11648/j.ajsea.20170606.11 